\title{
CLINICAL OBSERVATIONS ON THE T WAVE OF THE AURICLE APPEARING IN THE HUMAN ELECTROCARDIOGRAM
}

\author{
By HOWARD B. SPRAGUE* aND PAUL D. WHITE \\ (From the Cardiac Clinic of the Massackusetts General Hospital, Boston)
}

(Received for publication, December 16, 1924)

There has been considerable difference of opinion during the development of electrocardiography as to the relationship between the electrical phenomena of the heart beat, as recorded by the electrocardiograph, and the attendant muscular activity. It has come to be generally held that the waves of the electrocardiogram indicate the spread of relative electrical negativity throughout the heart from the region of the sino-auricular node to the various parts of the heart's musculature. The electrical energy propagated in this manner has been the expression of the so-called "excitation wave."

Much physiological research has been undertaken in an attempt to demonstrate the time relationship between this "excitation wave" and the muscular contraction of the heart. In general most of such work has been by the method of simultaneous registration of electrocardiographic and myocardiographic records in such a manner that they can be compared, and the sequence of events studied and measured. Similar comparisons have been made between electrocardiograms and intracardiac pressure curves. Myocardiographs have been devised by Cushny, Roy, Gesell, Wiggers and others, and have been used in connection with the string galvanometer, for which we are indebted to Professor W. Einthoven.

By the extensive researches of Garten and Weber, Wiggers, Lewis, Feil and Stroud, Wiggers and Dean, and others, it became generally recognized that the "excitation wave" precedes the muscular contraction of the heart by a definite and constant interval. Wiggers (1)

\footnotetext{
- Dalton Scholar 1924-1925, Massachusetts General Hospital.
} 
says "comparison of the $\mathrm{P}_{2}$ wave with the intra-auricular pressure curves indicates that auricular systole begins near the S-A node about 0.02 second after the rise of $\mathrm{P}_{\mathbf{2}}$ (Garten and Weber, Wiggers), i.e., on its ascending limb. Not until 0.04 second later, however, or until the entire $\mathbf{P}$ wave has been completed, has the tissue near the right auricular appendage even begun to contract." Similarly "as regards the relation of the $R$ wave to the onset of ventricular systole, most of the earlier experimental evidence favors the idea that the $\mathbf{R}_{\mathbf{2}}$ variation is practically completed before mechanical systole has begun." Wiggers found that "the onset of the (intraventricular) pressure rise is uniformly somewhat later, that is, 0.03 to 0.045 second after the initial rise of the $R_{\mathbf{2}}$ wave. It is significant, therefore, that the $\mathbf{R}_{\mathbf{2}}$ wave precedes by a short though definite interval the first evidence of mechanical activity in the ventricle." So far as the T wave was concerned he concluded that "it is quite evident that the end of ventricular systole cannot be definitely related to any phase of the $T_{2}$ variations."

So firmly had the idea of an electrical wave spreading throughout the heart in advance of mechanical response been fixed in the theory of cardiac activity that it seemed one of the axioms of physiology.

In October, 1924, Professor Einthoven delivered at the Harvard Medical School the Dunham Lectures. His subject was "The Relation of the Mechanical and Electrical Phenomena of Muscular Contraction with Especial Reference to Cardiac Musculature." In these lectures he presented evidence to prove that the electrical phenomena of both skeletal and cardiac muscle do not precede the mechanical activity but are in every case absolutely coincident, and also that in force as well the electrical and mechanical phenomena are uniform. He maintained that with the apparatus used by previous investigators it was impossible for myograms recorded by them to show either the initial activity or minimal extent of muscular contraction. In particular he disagreed with previous findings showing a latent period between the "excitation wave" and the muscular response in skeletal and cardiac muscle; he also showed that observations on dying hearts which were said to show electrical activity after cessation of mechanical action were incorrect.

In proving his view he described an apparatus which he had devised 
whereby photographic records of muscular action could be made by means of a frictionless lever and high magnification. Simultaneous records obtained with this apparatus and with the string galvanometer demonstrated the precise coincidence of electrical and muscular activity. In experiments on artificially poisoned hearts he was able to show not only that electrical and muscular phenomena begin and stop at the same instant, but that the amplitudes of the curves in hearts that are slowly dying or undergoing recovery are perfectly comparable in magnitude. In other words, diminution of muscular activity is accompanied by a corresponding diminution in the size of the electrical complexes; and increase in contractile power, as measured in the myocardiogram, is perfectly reflected in an increased amplitude of the electrocardiographic waves.

The application of this work to human cardiology affords further important proof of Einthoven's thesis. This is connected with a study of the $P$ wave of the electrocardiogram. In the early work in electrocardiography it was thought to be improbable that the relatively long activity of auricular systole could be accurately represented by such a momentary phenomenon as the $P$ wave of the electrocardiogram. Measurements readily showed that the duration of the contraction of auricular muscle was far greater than the time expressed by the $\mathrm{P}$ deflection. It would, therefore, seem difficult to reconcile the muscular and electrical activities in the case of the auricle-a situation more easily capable of explanation in the ventricular records because of the existence of the $T$ wave, which may be shown to have a relationship with the end of ventricular systole.

Einthoven, however, has brought forward some important observations bearing on this subject. He pointed out that $\mathrm{H}$. E. Hering (2) had noted in 1908 that under certain circumstances it was possible to demonstrate that the auricle also had a $\mathrm{T}$ wave associated with its contraction. Hering found this wave in electrocardiograms from a frog's heart. He also observed a similar wave in records from a dog's heart in which the auricles only were beating, as the ventricles were in fibrillation from the action of curare. Other workers, Straub (3), Henle (4), and Eiger (5), had previously published electrocardiograms from frogs showing such curves, which they were unable to explain. Noyons (6) in 1910 had also made similar observations on the cold-blooded heart. 
Experiments on frogs' hearts by Samoljoff (7) in 1908 had revealed a wave which he called the $B$ wave, as he attributed it to muscular activity in the bulbus aortae. Hering, in repeating these experiments, cut away the bulb and found that this wave continued to be recorded. He therefore concluded that it did not arise in the bulb. By producing premature ventricular contractions, Hering was able to make this wave fall upon the $R$ wave and also to follow the $R$ wave, but again observed that its relationship to $\mathbf{P}$ and its form were not influenced by ventricular activity. He therefore came to the conclusion that it represented a $T$ wave of the auricle, and suggested naming it the "Ta" wave.

Bakker (9) in 1912 demonstrated an auricular $T$ wave in the eel's heart. In the same year Fredericq (8) published an article on the nature of auricular systole, with electrocardiograms from dogs' hearts, showing that the electrical record from the auricle was essentially the same as that from the ventricle and consisted in an early rapid deflection followed by a curve which was much slower in its rise and fall.

Eiger (10) in 1913 added greatly to this study by an article on the electrocardiogram in which he showed that not only the ventricle and auricle have $T$ waves connected with their activity but also that the bulbus aortae and sinus venosus have such waves. Veen (11) the following year made a further contribution and suggested a different nomenclature for the waves.

Eyster and Meek (12) in 1913 published electrocardiograms showing auricular $T$ waves in records from the tortoise heart in which the ventricle had ceased to beat as the result of the application of a second Stannius ligature. In addition they found such waves in electrograms taken from isolated strips of ventricular muscle. They also demonstrated auricular $\mathrm{T}$ waves in electrocardiograms from dogs' hearts in which there was heart block from morphin, from pressure in the region of the auriculo-ventricular node, and from vagus stimulation. ${ }^{1}$

Rümke (13) in 1916 summarized this literature and again emphasized the viewpoint that isolated parts of the heart show electro-

$1 \mathrm{~J}$. Meakins (Heart, 1913-1914, v, 287 and 288) also published electrocardiograms from dogs showing "Sa" waves. Figs. 4, 7 and 8. 
grams in which initial deflections are followed by $T$ waves, and that leads from any two parts of the heart will record such combined deflections as the inherent phenomena of muscular contraction.

The presence of an auricular $\mathrm{T}$ wave in the human electrocardiogram has been, of course, suspected, but under normal circumstances it can not be demonstrated, due to the fact that the Ta wave in such cases occurs at the same time as the QRS complex and its relatively low potential has no appreciable influence on the form of the ventricu. lar wave. Theoretically, therefore, it would be possible to demonstrate the Ta wave only where one could isolate the auricular complex in its entirety from the ventricular response. Such a condition exists in heart block and is most favorably shown in complete block in which it is possible to see $P$ waves occurring as isolated complexes uninfluenced by the contiguity of QRS groups.

The presence of auricular $T$ waves in cases of heart block has long been known and has recently been described by a Japanese worker. ${ }^{2}$ Einthoven has found in the discovery of the auricular $T$ wave another instance of electrical activity paralleling muscular contraction. $\mathrm{He}$ has been able to relate it to the terminal phase of auricular systole in the same manner that the ventricular $T$ wave is related to ventricular activity. It is the clinical electrocardiographic demonstration of this $\mathrm{Ta}$ wave in cases of heart block that we wish to note in this observation.

\section{ELECTROCARDIOGRAPHIC OBSERVATIONS}

In the past 10 years in the Cardiac Clinic of the Massachusetts General Hospital, 37 cases of complete heart block have come under observation, and have been studied by electrocardiograms. It was decided to review the records of these patients in an attempt to discover whether or not any of them showed the presence of Ta waves. Certain difficulties in the determination of these waves were immediately obvious: (1) the records must be technically accurate, free from any marked somatic tremor or extraneous deflections; (2) they must show solitary auricular complexes sufficiently isolated as to be

${ }^{2}$ Personal communication from Prof. Einthoven. We have been unable to find this reference. Auricular $\mathrm{T}$ waves have also been described in the human electrocardiogram by Boden and Neukirch (18) and by Boden (19). 
uninfluenced by any QRS or ventricular T deflections; and, (3) the preceding conditions must occur in cases in which the Ta wave is not isoelectric, as we must suppose it sometimes is, in analogy with the ventricular $T$ wave.

In this series of 37 cases of complete heart block we were able to demonstrate a Ta wave in 18 instances, and in 7 more a questionable Ta wave could be seen. In addition it was clearly shown in one case of high grade partial block, with a 3:1 ratio of auricular and ventricular beats.

Table 1 shows the amplitude of the Ta deflections in general terms.

The $\mathrm{Ta}$ wave is of very low potential and in none of these cases does the deflection exceed $2 \mathrm{~mm}$. in height with normal tension of the electrocardiographic string (standard of 1 millimeter excursion for each tenth of a millivolt of potential). However, in this series

TABLE 1

Amplitude of $T a$ waves in series of 37 heart block cases

\begin{tabular}{c|c|c|c|c|c}
\hline & $\begin{array}{c}\text { No Ta } \\
\text { wave } \\
\text { demonstra- } \\
\text { ble }\end{array}$ & $\begin{array}{c}\text { Question- } \\
\text { able } \\
\text { Ta wave }\end{array}$ & $\begin{array}{c}\text { Slight } \\
\text { diphasic or } \\
\text { inverted } \\
\text { Ta wave }\end{array}$ & $\begin{array}{c}\text { Moderate } \\
\text { Ta wave }\end{array}$ & $\begin{array}{c}\text { Marked } \\
\text { Ta wave }\end{array}$ \\
\hline Number of cases................... & 12 & 7 & 6 & 8 & 4 \\
\hline
\end{tabular}

approximately one-half of the cases show waves following the $\mathbf{P}$ waves at constant intervals which must be interpreted as being the $\mathrm{T}$ deflections of the auricular complexes.

The initial deviation of the Ta wave in these cases was constantly negative, i.e., in the opposite direction to the $\mathrm{P}$ wave, and the whole complex seemed typically to be represented as a diphasic $P$ wave in which the return to the base line was gradual. In the most marked cases a very short isoelectric period separates the $P$ and Ta waves.

Simple measurements, without the use of a comparator, show that the $\mathrm{Ta}$ wave varies in length from 0.22 to 0.26 of a second. The total duration of the auricular complexes from the beginning of the $P$ wave to the end of the Ta wave varies from 0.34 to 0.42 of a second. Measurements from the electrocardiograms of the cases in which the Ta wave was most obvious appear in table 2.

It will be seen from this table that the average total length of the 
auricular complexes is about equal to three and a half times the average length of the $P$ wave. It is also evident that the average $T a$ wave differs from the average $T$ wave of the ventricle in deviating from the base line earlier after the end of the $P$ wave than does the $T$ after the QRS. The isoelectric period, therefore, is very short $(0.01$ to 0.05 of a second) and often is almost indistinguishable.

TABLE 2

\begin{tabular}{c|c|c|c|c}
\hline Case & Length of $\mathrm{P}$ wave & $\begin{array}{c}\text { Length of isoelectric } \\
\text { period between } \\
\mathrm{P} \text { and Ta }\end{array}$ & Length of Ta wave & $\begin{array}{c}\text { Total length of } \\
\text { auricular complexes }\end{array}$ \\
\cline { 5 - 5 } & seconds & seconds & seconds & seconds \\
I & 0.12 & 0.04 & 0.26 & 0.42 \\
II & 0.08 & 0.05 & 0.23 & 0.36 \\
III & 0.11 & 0.02 & 0.23 & 0.36 \\
IV & 0.10 & 0.01 & 0.25 & 0.36 \\
IV & 0.10 & 0.02 & 0.22 & 0.34 \\
V & 0.13 & 0.03 & 0.22 & 0.38 \\
\hline Average......... & 0.106 & $0.03-$ & $0.23+$ & 0.37 \\
\hline
\end{tabular}

TABLE 3

Comparison of electrocardiograms and myograms taken simultaneously from experimental animals

\begin{tabular}{|c|c|c|c|c|}
\hline Author & $\begin{array}{l}\text { Experi- } \\
\text { mental } \\
\text { animal }\end{array}$ & $\begin{array}{l}\text { Length of } \\
P \text { wave }\end{array}$ & $\begin{array}{l}\text { Latent } \\
\text { period of } \\
\text { auricular } \\
\text { muscle }\end{array}$ & $\begin{array}{l}\text { Length of } \\
\text { auricular } \\
\text { myogram }\end{array}$ \\
\hline & & seconds & seconds & seconds \\
\hline Lewis, Meakins, and White (14). . & Dog & 0.06 & 0.03 & 0.16 \\
\hline Lewis $(15) \ldots \ldots \ldots \ldots \ldots \ldots$ & Dog & 0.04 & 0.015 & 0.16 \\
\hline Lewis and White (16)...... & Dog & 0.06 & 0.03 & 0.14 \\
\hline Kraus and Nicolai (17)............... & Dog & 0.08 & 0.10 & 0.20 \\
\hline Avera & & 0.06 & 0.044 & $0.16+$ \\
\hline
\end{tabular}

In order to establish a relationship between the length of the total auricular complex and the muscular activity of the auricle it was decided to study the relative length of the $P$ wave in experimental animals compared to the myocardiographic records of the auricles.

If the P-Ta complex were an accurate measure of the muscular contraction one might expect to find that the length of the $\mathrm{P}$ wave was about one-third of the total length of the auricular myogram added 
to the latent period of the muscle. As the $P$ wave is quite variable in length this ratio can only be an approximation. Comparative measurements from electrocardiograms and myograms taken by various workers appear in table 3.

From these figures it appears that the ratio is roughly what one would expect, the $\mathrm{P}$ wave in each instance having a duration of about one third to one quarter of the auricular myogram plus its latent period. ${ }^{3}$ This is further evidence that the P-Ta complex is an exact measure of auricular muscle activity.

The cases of our series in which the Ta wave is most marked are summarized below, and are illustrated by electrocardiograms showing the characteristic appearance of the $\mathrm{Ta}$ wave.

Case 1. D. H. D. Garage Manager. Age 53. First seen April 13, 1917, when he was admitted to the Massachusetts General Hospital complaining of syncopal attacks for 8 months associated with a pulse rate of 35 . There was a very vague history of syphilis and the blood Wassermann was negative. Electrocardiogram showed complete heart block with ectopic ventricular contractions. The ventricular rate sometimes dropped to 24. A diagnosis of heart block with StokesAdams attacks, probably arteriosclerotic in origin, was made. He died in 1919.

Case 2. C. A. P. Salesman. Age 45. Seen first November 30, 1916, complaining of fatigue for 4 months, with attacks of faintness without loss of consciousness. His pulse suddenly dropped to 26 during an attack. Electrocardiogram showed partial and complete $\mathrm{A}-\mathrm{V}$ block; in one instance with eleven auricular beats without one ventricular response. There was a suspicious history of syphilis and the blood Wassermann was moderately positive. A diagnosis of heart block, probably of luetic origin, with Stokes-Adams syndrome, was made. He died in April, 1917.

Case 3. J. E. R. Shipping clerk. Age 52. Seen first February 9, 1922, with a complaint of dyspnea on exertion for a few months and sudden attacks of syncope. His pulse varied from 20 to 45 and auricular sounds were clearly audible. Electrocardiogram showed high grade partial A-V block, 2:1 and 3:1, and at times complete dissociation. A diagnosis of arteriosclerotic heart disease with heart block and Stokes-Adams attacks wasmade. He died suddenly in November, 1923.

${ }^{3}$ The ratio of the average length of the $P$ wave to the average length of the auricular complex in the human electrocardiogram, in the cases measured, is 1: 3.49. The ratio of the $\mathbf{P}$ wave to the auricular myogram, in the case of the experimental animals, is $1: 3.4$. As the series in both instances is so small such close agreement cannot be considered as necessarily constant. 
Case 4. P.S. Girl. First seen by Dr. Edwin H. Place in 1907, aged 2-3 years, with tonsillar diphtheria. There was a rather indefinite story of congenital heart disease which was not demonstrable when she was first observed. On the third day of her diphtheria her pulse suddenly dropped from 120 to 50 . She recovered from her infection but the slow rate has persisted ever since, never going above 50 . Electrocardiographic study in 1916 and 1919 showed complete A-V block. When she was last seen in the Spring of 1924 she was feeling perfectly well. There is doubt as to the actual causation of this permanent block by the diphtheria in the absence of other evidence of serious myocardial damage or peripheral paralysis.

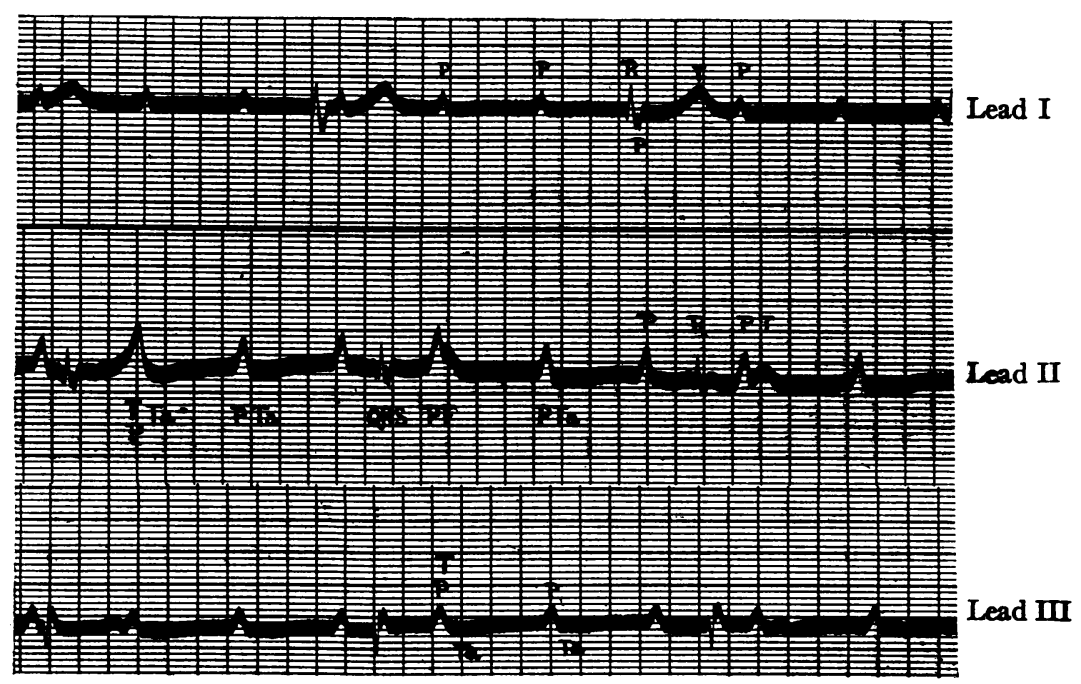

\section{Fig. 1. (Case 1.) Clearest Ta Wayes in Lead II, Less Distinct in LEAD III, ALmost IsOLLeGTric IN LEAD I}

Case 5. E. D. G. Student. Age 24. First seen January 5, 1924, when he was admitted to the Massachusetts General Hospital with a cellulitis of the neck and osteomyelitis of the jaw following the extraction of abscessed teeth. He developed precordial pain and friction rub, and it was thought that he had acute pericarditis and mediastinitis. During the acute period of his illness his pulse suddenly dropped from 88 to 40 , and electrocardiograms showed high grade partial block $(3,4$, and 5 to 1 ratio of auricular and ventricular beats). At times sounds suggestive of auricular contractions were heard. The heart block disappeared in about 5 days and he recovered. His heart showed no signs of endocarditis and there was no pericardial effusion. A diagnosis of toxic or bacterial myocarditis with heart block was made. 


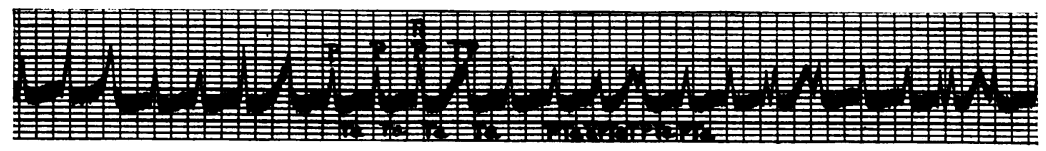

Fig. 2. (Case 1.) Well Marked Ta Waves Throughout Lead II. High $P$ WAVES

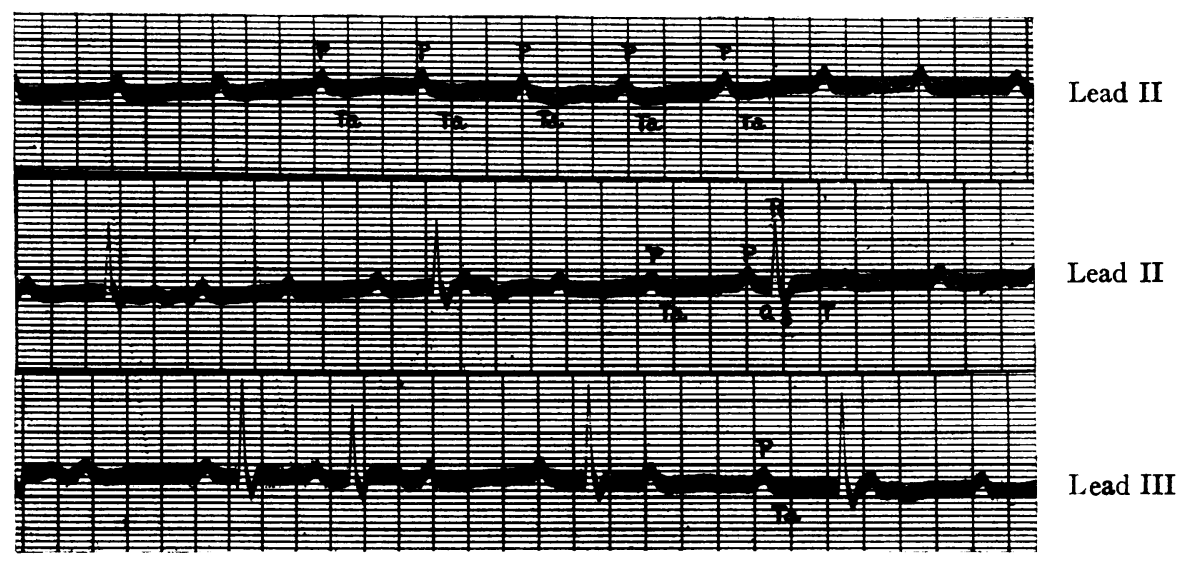

Fig. 3. (Case 2.) Eleven Auricular Waves in Lead II With No Ventricular Response. Ta Waves Well Marked in All Leads

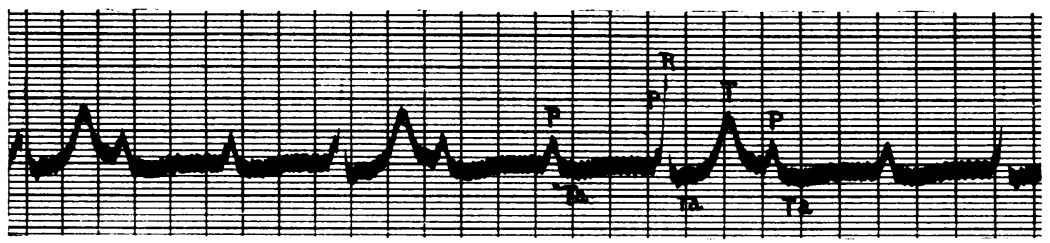

Fig. 4. (Case 3.) Distinct Ta Waves, Every Third One Being Partly Obscured by the Ventricular Complexes

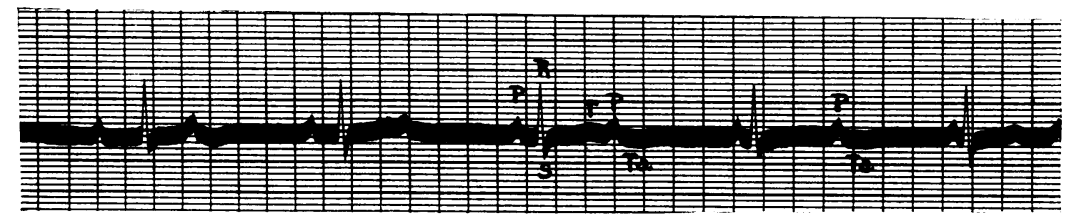

Fig. 5. (Case 4.) Well Marked Ta Waves, at Times Obscured Ventricular Complexes 


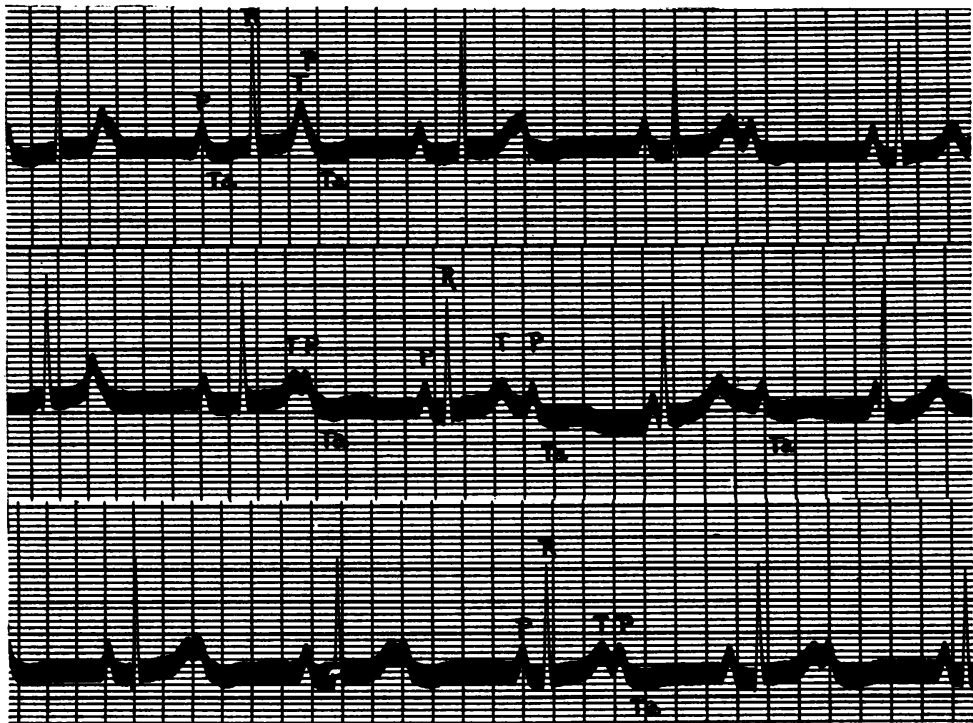

Lead II

Lead II

Fig. 6. (Case 4.) Very Distinct Ta Waves in All Records

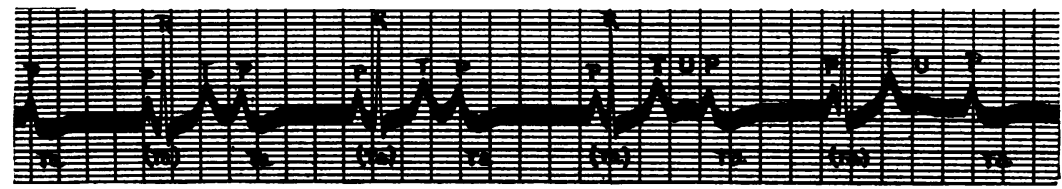

Fig. 7. (Case 4.) Very Distinct Ta Waves Throughout Lead II

Note auricular arrythmia and the appearance of well defined U Waves. Alternate Ta Waves masked by QRS complexes.

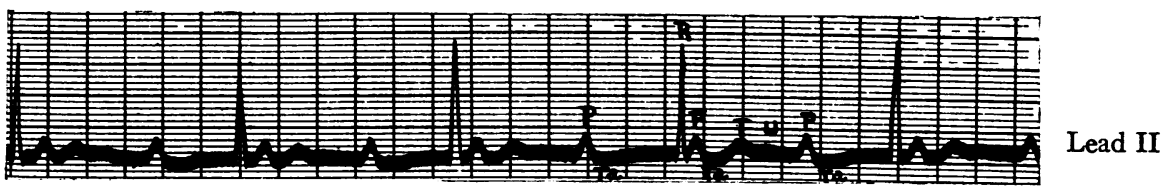

Fig. 8. (Case 4.) Electrocardiogram (Lead II) Taken Three Years After THE ONes Shown IN Figures 5, 6, aNd 7

The block still persists and the Ta and U Waves are still obvious. 


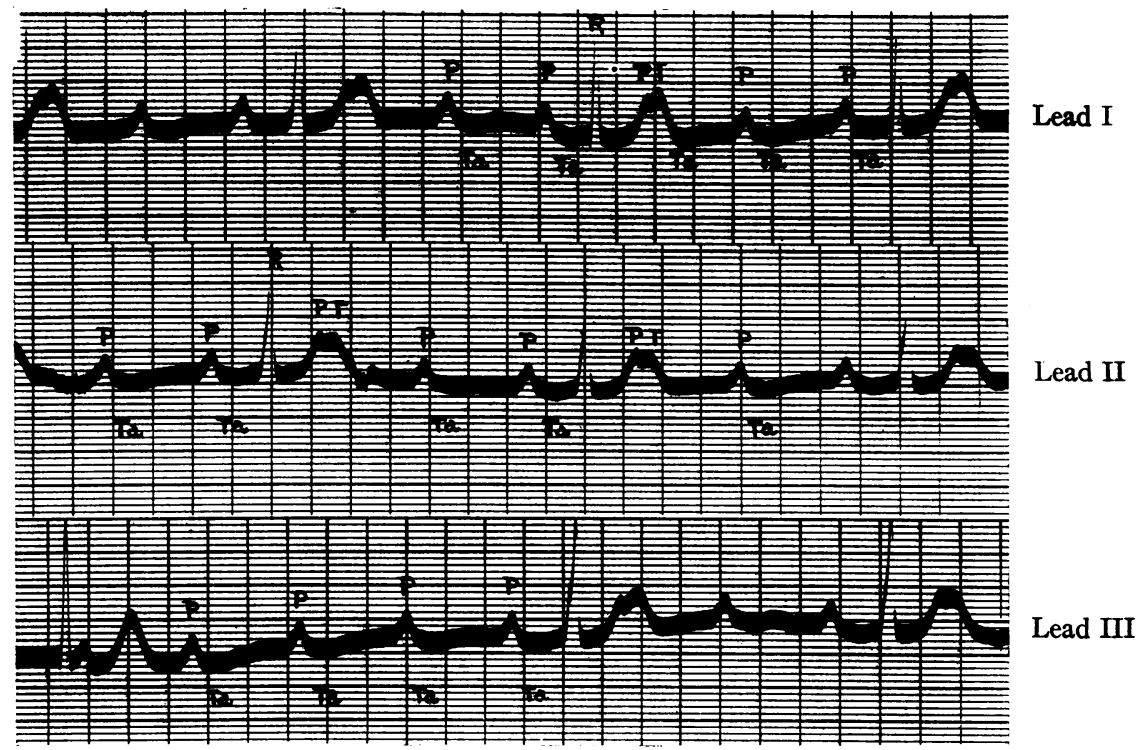

Fig. 9. (Case 5.) Distinct Ta Waves in Three Records from lead II

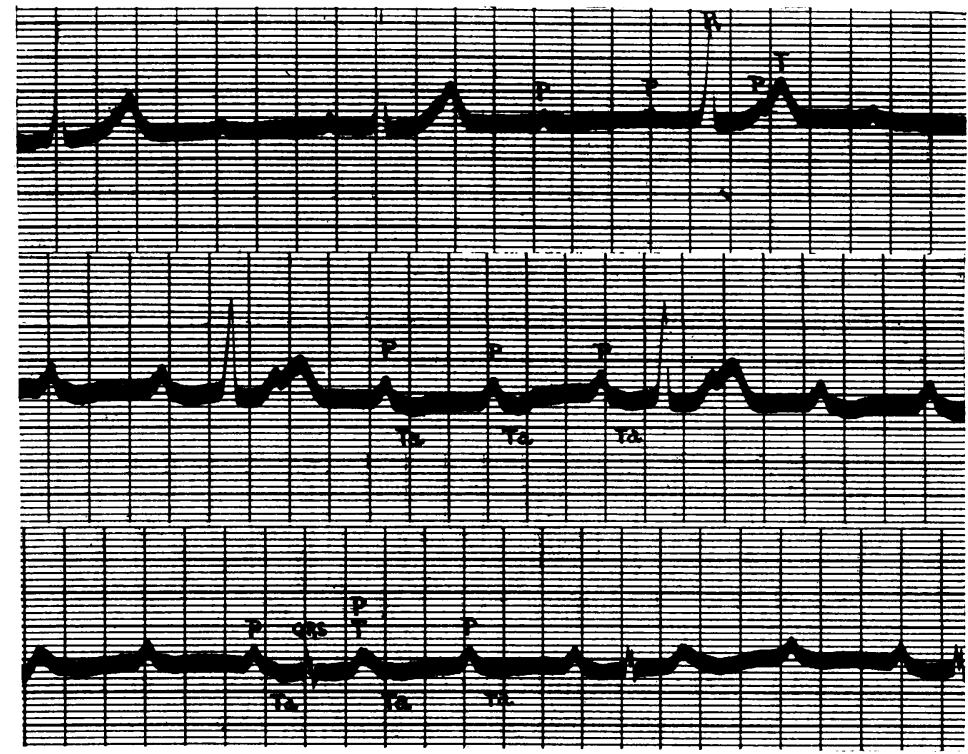

Fig. 10. (Case 5). Very Well Marked Ta Waves in Lead II

The isoelectric period between $\mathrm{P}$ and Ta can be made out. Note the less distinct Ta Waves in Lead III and the almost flat Ta Waves in Lead I. 


\section{SUMMARY}

1. The generally recognized opinion concerning cardiac mechanism includes the theory of an electrical "wave of excitation" spreading throughout the heart by way of the conducting system, slightly in advance of the attendant muscular contraction. This theory is based on simultaneously recorded myocardiographic and electrocardiographic waves.

2. Professor W. Einthoven has recently denied the existence of this latent period and has described apparatus by which he has been able to record electrocardiograms and myocardiograms that show that electrical and muscular activity are precisely coincident. Previous observations, he asserts, are faulty because of the inadequacy of the apparatus used.

3. In support of his position Einthoven quotes the discovery of Hering and others that the auricular complex of both cold and warm-blooded animals has a terminal deflection, or $\mathrm{T}$ wave, which Hering called the Ta wave.

4. We have been able to find a Ta wave occurring after the $P$ wave in electrocardiograms of clinical cases showing complete or high grade partial A-V block. This wave was found in 18 out of 37 cases of complete block seen at the Massachusetts General Hospital.

5. The duration of the $\mathrm{P}$ wave in the human electrocardiogram is about one third of the total duration of the P-Ta complex. This is consistent with the findings in experimental animals that the $P$ wave is approximately one third to one quarter as long as the auricular myogram plus its "latent period" and supports the view that the $\mathrm{Ta}$ wave is an accurate expression of the terminal phase of auricular muscle activity.

\section{BIBLIOGRAPHY}

1. Wiggers, C. J. Modern Aspects of the Circulation in Health and Disease. 2nd. ed. Philadelphia, 1923, Chap. xv.

2. Hering H. E. Archiv. f. d. ges. Physiol., 1912, cxliv, 1. Uber die Finalschwankung des Vorhofelektrokardiogramms.

3. Straub, H. Zeitschr. f. Biol., 1910, liii, 499. Zur Analyse des Elektrokardiogramms (nach Versuchen am isolierten Froschherzen).

4. Henle, K. Zeitschr. f. Biol., 1910, lv, 295. Uber die Beeinflussung des Elektrokardiogramms durch die polare Wirkung des konstanten Stromes. 
5. Eiger, M. Extrait du Bulletin de l'Academie des Sciences de Cracovice, July, 1911.

6. Noyons, A. K. M. Onderz. Physiol. Lab. Utrecht., 1910, xi, 214. Communications about the Electrocardiogram of the Atrium.

7. Samoljoff, A. Beitr. z. Physiol. u. Pathol. Stuttgart, 1908. Elektrokardiogrammstudien.

8. Fredericq, H. Arch. Internat. de Physiol., 1912, xii, 66. Sur la Nature de la Systole de l'Oreillette.

9. Bakker, Nelly C. Zeitschr. f. Biol., 1912, lix, 335. Analyse des Elektrokardiogramms auf Grund von am Aalherzen ausgefuhrten Untersuchungen.

10. Eiger, M. Archiv. f. d. ges. Physiol., 1913, cli, 1. Die physiologischen Grundlagen der Elektrokardiographie.

11. Veen, H. Ned. Tijschr. v. Geneesk., 1914,ii, 1924. Een Onderzoek van eenige Contractiliteitsuitingen der Hartspier.

12. Eyster, J. A. E., and Meek, W. J. Arch. Int. Med., 1913, xi, 201. The Interpretation of the Normal Electrocardiogram.

13. Rümke, H. C. Arch. Neederland. de Physiol., 1916-1917, i, 161. Sur Quelques Electrogrammes de Lambeaux du Grenouille.

14. Lewis, T., Meakins, J., and White, P. D. Phil. Trans., Series B, ccv, 42. The Excitatory Process in the Dog's Heart.

15. Lewis, T. The Mechanism and Graphic Representation of the Heart Beat. 2nd Ed. London, 1920, p. 50, fig. 26.

16. Lewis, T., and White, P.D. Unpublished record of experimental work on the effect of vagus stimulation on the dog's heart.

17. Kraus and Nicolai. Das Elektrokardiogramm des Gesunden und Kranken Menschen. Leipzig, 1910, p. 152, fig. 47.

18. Boden, E., and Neukirch, P. Arch. f. d. ges. Physiol., 1918, clxxi, 146. Electrokardiographische Studien am isolierten Säugetier- und Menschenherzen.

19. Boden, E. Münch. Med Wchnschr., 1921, lxviii, 1104. Beobachtungen über eine Nachschwankung des Vorhofselektrokardiogramms am isolierten Saügetier- und Menschenherzen. 